\title{
The Use of Contact Lenses by Army Air Crew
}

\section{Major M G Braithwaite}

$\mathrm{MB}, \mathrm{ChB}, \mathrm{RAMC}$

Specialist in Aviation Medicine,

Army Air Corps Centre, Middle Wallop

SUMMARY: Since 1974 seven Army pilots have been allowed to wear contact lenses for flying. This paper records their flying experience using this form of visual correction and discusses the advantages and disadvantages of contact lens use by military aircrew. Recommendations for future policy are suggested.

\section{Introduction}

The use of soft contact lenses in flight by RAF aircrew has recently been the subject of a trial at the RAF Institute of Aviation Medicine (IAM). The trial is complete but the report is yet to be published. The Army is the only service to permit some pilots to fly wearing contact lenses. Currently 7 Army pilots are allowed to do so. Because of the recent interest in this aspect of aviation medicine, these personnel were questioned about their experience with contact lenses. This paper aims to discuss the use of contact lenses by military aircrew and make recommendations for future policy.

\section{Background}

Corrected flying spectacles of various types have been prescribed in military and civil aviation for over 35 years. Current aircrew spectacles give good and stable correction of central vision, both for distance and near sight. They have proved to be an excellent means of retaining trained aircrew in the flying role. However, spectacles have disadvantages:

(a) helmet design restricts the width of spectacle frames hence obstructing the peripheral visual fields, and spectacle arms may interfere with helmet fit and reduce noise attenuation.

(b) They are not compatible with military night vision aids or weapon sights. A specialized frame is required for respirator use.

(c) Plastic safety lenses scratch more easily and tend to mist readily in hot or damp environments.

(d) Spectacle lenses may cause severe ocular injury in aircraft accidents.

Contact lenses appear to overcome many of these problems. They would also improve vision outside the aircraft in inclement weather. Balanced against these advantages, contact lenses have many drawbacks for the military aviator: (a) Initial fitting of lenses must be under the supervision of a consultant ophthalmologist acquainted with the problem of aviation, and long term tolerance must be proved on a ground tour.

(b) Only the new 'extended wear' lenses can be worn while sleeping. Other types must be re moved for sleep and hence reaction time or $\vec{N}$ operational duty is lengthened while the lense are inserted.

(c) Contact lenses may absorb atmospheric pollut ants, and foreign bodies have a more damaging effect on the cornea when lenses are worn.

(d) Corneal hypoxia is less of a problem with sof lenses but the effect of altitudes may aggravate this phenomenon. At cabin altitude of 20,000 feet and above gases dissolved in the tear fluiç can produce bubbles which degrade vision and; if the lenses are not removed, can produce corneal abrasions. (Such altitudes are rarely achieved by Army pilots).

(e) Soft lenses need to be well hydrated. Dry conditions or exposure to airflow reduces the optical quality and produces discomfort.

(f) Most contact lenses require scrupulous cleaning. This is difficult in the best of field conditions and impossible in a chemically contaminated environment.

(g) The loss of a contact lens in flight may have serious consequences.

\section{Review of Current Policy}

Ophthalmic standards for Army aircrew selection are high and are currently Right 6/12 Left 6/12 correctable to Right $6 / 6$ Left $6 / 6$. There is no reason why these standards should be changed whilst there are adequate numbers of suitable applicants. Spectacles are prescribed for established aircrew when vision deteriorates. Originally the Army did not 
allow aircrew to wear contact lenses. However, in 1974 following representation to the Specialist in Aviation Medicine, 2 pilots who felt they could fly safely and efficiently wearing contact lenses were flight tested. Comprehensive evaluation in a Gazelle aircraft was performed, as a result of which the Department of Aviation Medicine changed its policy. It is now in line with The Civil Aviation Authority for private pilots viz., "aircrew may wear contact lenses if tolerence has been proved by wearing for 16 hours a day over a period of 6 months on ground duty." A waiver to the pilot's medical category is applied, such aircrew being graded as "P2 FE A3 G2 Z1, 'to wear contact lenses and carry corrective flying spectacles on flying duty.'

\section{Method}

An open questionnaire requesting details of contact lenses, hours flown and type of aircraft was sent to all 7 pilots. They were also asked to comment on particular problems, advantages and disadvantages of their contact lenses. A $100 \%$ response rate was achieved. Factual results are shown in table 1. lenses mentioned photosensitivity as a minor problem easily overcome by the use of the tinted visor. Only one pilot had served an operational tour whilsto wearing contact lenses. His main comment was the inability to become operational immediately on beingo woken from sleep although this was a rare occur-c? rence.

\section{Discussion}

All subjects are currently in posts which require $\frac{\overline{\frac{\sigma}{5}}}{\frac{1}{7}}$ little flying. Indeed most are of the age group in尺 which administrative posts are more common than operational flying tours. It is within this age range. that the need for optical correction is most likely to? present. Unfortunately, because of the nature of their $\overrightarrow{\vec{\omega}}$ posts, few comments about the suitability of contacto lenses for field use were obtained.

The acceptability of soft contact lenses for use by United States Army aircrew was studied in 19741. The subjects were established aircrew wearing corrective flying spectacles. Although limited in scope, the following conclusions were made:

(a) Provision of lens cleaning facilities is paramoug $\vec{N}$

Table 1

Results: Summary of flying of pilots who wear contact lenses

\begin{tabular}{|c|c|c|c|c|c|c|c|}
\hline Subject & Age & $\begin{array}{l}\text { Reason for } \\
\text { Optical } \\
\text { Correction }\end{array}$ & $\begin{array}{l}\text { Spectacles } \\
\text { worn for } \\
\text { (years) }\end{array}$ & $\begin{array}{l}\text { Lenses } \\
\text { worn for } \\
\text { (years) }\end{array}$ & $\begin{array}{c}\text { Type of } \\
\text { Lens }\end{array}$ & $\begin{array}{l}\text { Hours flown } \\
\text { during use } \\
\text { of lenses }\end{array}$ & $\begin{array}{ll}\text { Type of } & \stackrel{8}{\varrho} \\
\text { aircraft } & 0 \\
\frac{0}{2}\end{array}$ \\
\hline 1 & 54 & Aphakia & 3 & 8 & hard & 380 & $\begin{array}{r}\text { Sx, Sc, Gz, } \\
\mathrm{Lx}, \mathrm{Cp}, \mathrm{Bvr}\end{array}$ \\
\hline 2 & 41 & Myopia & Nil & 12 & hard & 1100 & $\mathrm{Sx}, \mathrm{Sc}, \mathrm{Gz}$ \\
\hline 3 & 50 & Aphakia & Nil & $\begin{array}{l}4 \\
3\end{array}$ & $\underset{\text { silicone }}{\text { soft }}\}$ & 30 & $\mathrm{Sc}, \mathrm{Gz}$ \\
\hline 4 & 31 & Myopia & $\begin{array}{c}14 \\
\text { (not flying) }\end{array}$ & $\begin{array}{l}2 \\
3 \\
2\end{array}$ & $\begin{array}{l}\text { hard } \\
\text { soft } \\
\text { extended } \\
\text { wear }\end{array}$ & $\begin{array}{c}\mathrm{Nil} \\
300 \\
150\end{array}$ & $\mathrm{Gz}$ \\
\hline 5 & 36 & Myopia & 3 & 5 & soft & 250 & $\mathrm{Sc}, \mathrm{Gz}$ \\
\hline 6 & 44 & Myopia & 2 & $\begin{array}{l}9 \\
1\end{array}$ & $\begin{array}{l}\text { hard } \\
\text { soft }\end{array}$ & $\begin{array}{r}1600 \\
200\end{array}$ & Sx, $\underset{\text { Lx }}{\text { Sc, Gz }}$ \\
\hline 7 & 31 & Myopia & $\begin{array}{l}15 \\
\text { (not flying) }\end{array}$ & $\begin{array}{l}2 \\
3\end{array}$ & $\begin{array}{l}\text { hard } \\
\text { soft }\end{array}$ & $\begin{array}{r}10 \\
400\end{array}$ & $\mathbf{G z}, \mathbf{L x}$ \\
\hline
\end{tabular}

Abbrs: Sx Sioux, Sc Scout, Gz Gazelle, Lx Lynx, Cp Chipmunk, Bvr Beaver.

Those who had previously worn spectacles mentioned most of the advantages of contact lenses stated earlier in this paper. All were certain that their visual correction was enhanced. Particular disadvantages mentioned were lens cleaning in the field and irritation in dry, dusty climates. One pilot experienced difficulty in self-centering a hard lens on one occasion when suddenly looking upwards to check an overhead instrument. One point with soft (b) Foreign body hazards were not identified with soft lenses despite the heavy rotor downwash of large aircraft.

(c) Flights under stress, particularly at night could $\stackrel{\circ}{\frac{1}{D}}$ result in a decreased blink rate due to the ten-0 dency to stare. This may increase the possibility of lens dehydration.

(d) Increased salinity of the tears caused by the 
high temperature and humidity in the area where the study was made helped to maintain lens tonicity. Discomfort of spectacles from perspiration was eliminated.

American Army aircrew are not permitted to wear contact lenses. Excepting cases of trauma and aphakia, current RAF policy does not permit aircrew to wear contact lenses ${ }^{2}$. The Royal Navy hold a similar view.

With the increasing sophistication in military aviation equipment, items are being developed which are not compatible with spectacle frames. To avoid a compromise some positive action must be taken. Alternatives are:

(a) Design the equipment to accommodate the spectacles or incorporate the spectacle power.

(b) Restrict the use of such equipment to nonspectacle wearers.

(c) Eliminate all ametropic aviators.

(d) Provide satisfactory contact lenses.

\section{Conclusions}

Current aircrew spectacles provide good visual correction. Disadvantages are due mainly to interference of the frames with safety and other equipment. Contact lenses overcome this incompatability but have many drawbacks of which tolerance, corneal damage risk and cleaning problems are the

most significant. Army Air Corps pilots who wear contact lenses are of the older age group. They are able to fulfil their limited fyying role but little experience has been gained on operational tasks while wearing contact lenses. Past American research has failed to initiate a change in policy. The results from a recent IAM trial are awaited.

When considering the prescription of contact lenses without specific medical recommendation, the following should be considered:

(a) Suitability must depend on the individual's circumstances of use. Extensive time spent in the field is not compatible with the use of contact lenses.

(b) Tolerance should be proved by achieving a wear time of 16 hours a day for 6 months. Soft lenses are generally better tolerated than hard lenses.

\section{Recommendations}

It is recommended that the present policy for the use of contact lenses by Army aircrew is maintained, and that the problem of incompatability of spectacle frames with new equipment be considered following publication of the RAF IAM contact lens trial report.

\section{Acknowledgements}

$I$ am grateful to the pilots concerned in this $\stackrel{P}{+}$ review for their prompt and comprehensive replieso to the questionnaire and to $\mathrm{Lt} \mathrm{Col}$ Ken Edgington RAMC for his guidance.

\section{REFERENCES}

Crosley J K, Braun E G and Bailey $R$ W. Softo (hydrophilic) Contact Lenses in US Army Aviations US Army Aeromedical Research Laboratory Report No $741974 ; 10$

2 Air Commodore Price T J G. "Why can't I wear" Contact Lenses?" Air Clues 1976.

RAMC CORPS WEEK EVENTS 1983

Annual Officers' Dinner

RAMC Officers "At Home"

AMS Sports Day

\section{Drumhead Service \& Association Luncheon}

HQ Mess, Millbank-Thursday, 23rd June, 1983.

HQ Mess, Millbank-Friday, 24th June, 1983.

Sports Stadium, Queens Avenue, Aldershot-Saturday, 25th June, 1983.

RAMC Training Group, Mytchett-Sunday, 26th June, 1983. 